\title{
Irreversible Hypersomnolence after Bilateral Thalamic Infarction
}

Sir,

Acute bilateral paramedian thalamic stroke (BPTS) is rare. In isolation, BPTS is most often secondary to occlusion of the artery of Percheron, a single dominant thalamoperforating artery arising from the initial segment of the posterior cerebral artery supplying both paramedian thalami. ${ }^{[1]}$ However, when combined with occipital posterior cerebral artery infarct, the "Top of the basilar syndrome" (TBS), which is caused by vascular disease of the distal basilar artery, should be considered. ${ }^{[2]}$ An 87-year-old right-handed female with medical history of hypertension, insomnia, and chronic back pain was found unresponsive at home. She was last seen in her normal health status $12 \mathrm{~h}$ earlier. She was admitted to the emergency department (ED) with a Glasgow Coma Score (GCS) of 9, hypotension (90/60 $\mathrm{mmHg})$, hypothermia $\left(36^{\circ} \mathrm{C}\right)$, and bradycardia $(40$ beats/min). The rest of the neurological examination was unremarkable. The complementary metabolic and toxic routine ED investigation yielded negative results. The brain computed tomography showed the presence BPTS and midbrain infarction [Figure 1a and b]. She was stabilized after supportive treatment few hours later. During hospitalization, she was newly diagnosed with hyperlipidemia and paroxysmal atrial fibrillation. The rest of stroke workup including the cervicocranial magnetic resonance angiography yielded negative results. Although the general status improved progressively, with hemodynamic stability, on the $3^{\text {rd }}$ day, a slight right-sided hemiparesis and an incomplete left-sided third nerve palsy were noticed. The brain magnetic resonance imaging showed the presence of BPTS, midbrain, and the left occipital lobe acute infarction [Figure 1c-f]. She was discharged after 2 weeks with persistent hypersomnolence, responding to motor stimuli and falling asleep in the absence of motor stimulation $(\mathrm{GCS}=10)$. The electroencephalogram did not show any epileptiform activity. After 3 months, she did not recover and kept remarkable hypersomnolence, precluding regain of autonomy (modified Rankin score of 4). The combination of behavior, oculomotor, and visual abnormalities without significant motor dysfunction is suggestive of TBS. ${ }^{[2]}$ In our patient, TBS was caused by distal basilar artery cardioembolic stroke due to atrial fibrillation. The presence of simultaneous occlusion of proximal left posterior cerebral artery, bilateral midbrain perforating branches as also bilateral thalamoperforating branches, caused the left occipital, the bilateral midbrain infarcts and the BPTS respectively. In majority of cases of BPTS or in cases of isolated midbrain lesions, progressive recovery of consciousness occurs. ${ }^{[1-3]}$ However, recovery in our patient was hampered by the presence of bilateral lesion of the paramedian thalamic nucleus which is involved in consciousness regulation as also damage of midbrain structures containing the reticular activating system. ${ }^{[3,4]}$ Our patient presented outside the formal time window for thrombolysis $(\leq 4.5 \mathrm{~h})$ and mechanical thrombectomy $(\leq 6 \mathrm{~h})$. However, mechanical thrombectomy can be performed with good results up until $24 \mathrm{~h}$ of basilar occlusion onset. ${ }^{[5]}$ Therefore, clinical suspicious of distal basilar disease should be considered in every patient presenting the combination arousal, ocular, visual, and motor dysfunction, particularly in the era of effective acute reperfusion interventions for large vessel occlusions. 

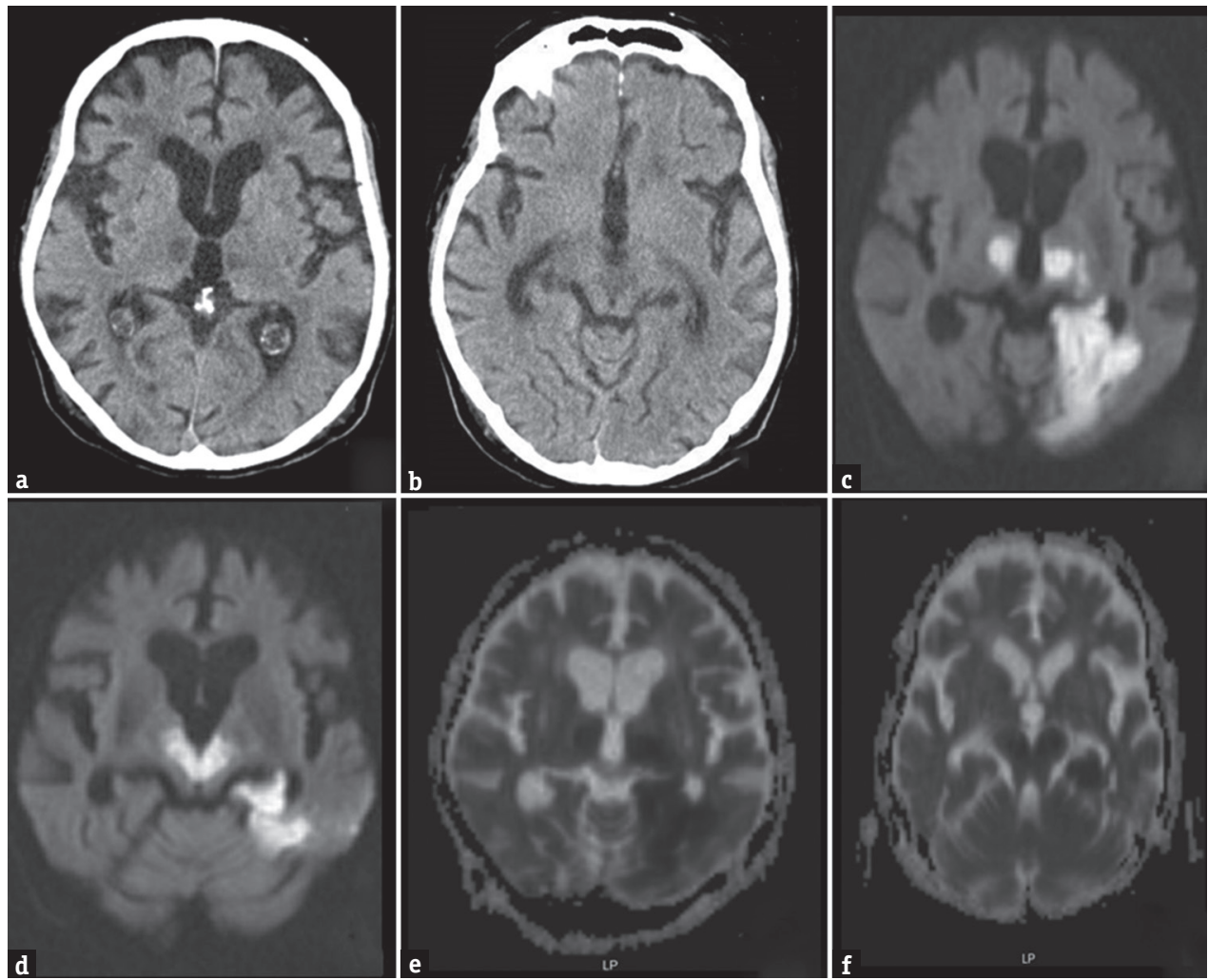

Figure 1: Noncontrast brain computed tomography scan showing bilateral medial thalamic and midbrain hypodensities (a and b); brain magnetic resonance imaging revealing bilateral medial thalamic, mesencephalic, and left territorial posterior cerebral hyperintense diffusion weighting (c and d); and hypointense ADC map (e and f) lesions

\section{Declaration of patient consent}

The authors certify that they have obtained all appropriate patient consent forms. In the form the patient(s) has/have given his/her/their consent for his/her/their images and other clinical information to be reported in the journal. The patients understand that their names and initials will not be published and due efforts will be made to conceal their identity, but anonymity cannot be guaranteed.

\section{Financial support and sponsorship}

Nil.

\section{Conflicts of interest}

There are no conflicts of interest.

Mihail Mogildea ${ }^{1}$, Miguel Varela ${ }^{1}$, Cristiana Martins ${ }^{1}$, Natércia Joaquim ${ }^{1,2}$, José Soleiro ${ }^{3}$, Hipólito Nzwalo ${ }^{2}$

Departments of ${ }^{1}$ Emergency and ${ }^{3}$ Neurology, Centro Hospitalar Do Algarve, ${ }^{2}$ Department of Biomedical Sciences and Medicine, University of Algarve, Faro, Portugal

Address for correspondence: Dr. Mihail Mogildea, Unidade De Faro, Centro Hospitalar Do Algarve, R. Leao Penedo, 8000-386 Faro, Portugal. E-mail:mihai-cim@hotmail.com

\section{REFERENCES}

1. Arauz A, Patiño-Rodríguez HM, Vargas-González JC, Arguelles-Morales N, Silos H, Ruiz-Franco A, et al. Clinical spectrum of artery of percheron infarct: Clinical-radiological correlations. J Stroke Cerebrovasc Dis 2014;23:1083-8.

2. Caplan LR. "Top of the basilar" syndrome. Neurology 1980;30:72-9.

3. Hermann DM, Siccoli M, Brugger P, Wachter K, Mathis J, Achermann P, et al. Evolution of neurological, neuropsychological and sleep-wake disturbances after paramedian thalamic stroke. Stroke 2008;39:62-8.

4. Yeo SS, Chang PH, Jang SH. The ascending reticular activating system from pontine reticular formation to the thalamus in the human brain. Front Hum Neurosci 2013;7:416.

5. Mak CH, Ho JW, Chan KY, Poon WS, Wong GK. Intra-arterial revascularization therapy for basilar artery occlusion-a systematic review and analysis. Neurosurg Rev 2016;39:575-80.

This is an open access article distributed under the terms of the Creative Commons Attribution-NonCommercial-ShareAlike 3.0 License, which allows others to remix, tweak, and build upon the work non-commercially, as long as the author is credited and the new creations are licensed under the identical terms.

\begin{tabular}{|l|l|}
\hline \multicolumn{2}{|c|}{ Access this article online } \\
\hline Quick Response Code: & Website: \\
& www.ruralneuropractice.com \\
\cline { 2 - 2 } & \\
\end{tabular}

How to cite this article: Mogildea M, Varela M, Martins C, Joaquim N, Soleiro J, Nzwalo H. Irreversible hypersomnolence after bilateral thalamic infarction. J Neurosci Rural Pract 2018;9:167-8.

(c) 2018 Journal of Neurosciences in Rural Practice | Published by Wolters Kluwer - Medknow 